\title{
EFEITO DA QUALIDADE FISIOLÓGICA DAS SEMENTES E DA DENSIDADE DE SEMEADURA SOBRE O RENDIMENTO DE GRÃOS E QUALIDADE INDUSTRIAL EM ARROZ ${ }^{1}$
}

\author{
ALBERTO HÖFS², LUIS OSMARBRAGASCHUCH ${ }^{3}$, SILMAR TEICHERTPESKE ${ }^{3}$,ANTONIO CARLOS SOUZAALBUQUERQUE BARROS ${ }^{3}$
}

\begin{abstract}
RESUMO - O experimento foi conduzido no Centro Agropecuário da Palma, da Universidade Federal de Pelotas (CAP/UFPel), com o objetivo de avaliar o efeito da qualidade fisiológica das sementes e da densidade de semeadura sobre o rendimento de grãos e qualidade industrial em arroz irrigado. Foram testados, em uma combinação fatorial em dois anos agrícola (2000/2001 e 2001/2002), dois níveis de qualidade fisiológica de sementes e diferentes densidades de semeadura. Os diferentes lotes de sementes da cultivar IRGA 417 foram obtidos junto a produtores de sementes credenciados junto à CESM/RS. As densidades de semeadura utilizadas foram $80,140 \mathrm{e} 200 \mathrm{~kg}$ de sementes por ha em 2000/2001 e 80 e $150 \mathrm{~kg}$ de sementes por hectare em 2001/2002. O uso de sementes de qualidade fisiológica mais alta proporcionou acréscimos no rendimento de grãos de $8,2 \%$ e $9,0 \%$, nos anos 2000/2001 e 2001/2002, que correspondeu a acréscimos de $622 \mathrm{~kg} \mathrm{ha}^{-1}$ e 660 $\mathrm{kg} \mathrm{ha}^{-1}$, respectivamente, enquanto que as diferentes densidades de semeadura não afetaram o rendimento de grãos por hectare. O uso de sementes de baixa qualidade fisiológica provocou desuniformidade na maturação, redução na massa de 1000 grãos, porém não afetou o rendimento de grãos inteiros e o índice de colheita. A variação na densidade de semeadura não afetou a uniformidade de maturação, o rendimento de grãos inteiros e a massa de 1000 grãos.
\end{abstract}

Termos para indexação: Oryza sativa L., qualidade de sementes, produção, rendimento de engenho.

\section{RICE SEED PHYSIOLOGICALQUALITY AND SEEDING RATE UPON GRAIN YIELD AND INDUSTRIAL QUALITY}

\begin{abstract}
An experiment was conducted in the Centro Agropecuário da Palma, at the Universidade Federal de Pelotas (CAP/UFPel) with the objective of evaluating the effect of rice seed physiological quality and seeding rate upon grain yield and grain integrity percentage. It was tested in a factorial combination in two crop years (2000/2001 and 2001/2002), two physiological quality levels and different seeding rates. Seed lots of the cultivar IRGA 417 were obtained from official seed growers of Rio Grande do Sul State, Brazil. Seeding rates were 80, 140 and $200 \mathrm{~kg}$ per hectare in 2000/2001 and 80 and $150 \mathrm{~kg}$ in 2001/2002. The use of high physiological quality level seed lots propitiated yield increases of $8,2 \%$ and $9,0 \%$ in 2000/2001 and 2001/2002, corresponding to $622 \mathrm{~kg} \mathrm{ha}^{-1}$ and $660 \mathrm{~kg} \mathrm{ha}^{-1}$, respectivelly. Otherwise, different seeding rates did not affect grain yield.The use of lots of low seed physiological quality caused uneven maturation, reduction in 1000 grain weight. On the other hand, grain integrity percentage and index of harvesting were not affected. The variation in the seeding rate did not affect maturation uniformity, grain integrity yield and weight of 1000 grains.
\end{abstract}

Index terms: Oryza sativa L., seed quality, crop yield, grain integrity percentage.

\footnotetext{
${ }^{1}$ Submetido em 06/11/2003. Aceito para publicação em 12/05/2004. Parte da Tese de Doutorado apresentada pelo primeiro autor junto ao Curso de Pós-Graduação em Ciência e Tecnologia de Sementes/UFPel, em 2003.

${ }^{2}$ Eng $^{\mathrm{o}} \mathrm{Agr}^{\mathrm{o}}$, Doutor, COODETEC, Rua Elizabete Campos, 246, Setor Morada
}

do Sol, 75908-780, Rio Verde, GO; e-mail: alberto@coodetec.com.br.. ${ }^{3} \mathrm{Eng}^{\mathrm{o}} \mathrm{Agr}^{\circ}$, Doutor, Professor, Depto. de Fitotecnia, FAEM/UFPel, Caixa Postal 354, 96010-900 - Pelotas, RS. 


\section{INTRODUÇÃO}

O arroz é consumido por mais da metade da população mundial, para atender sua necessidade diária de energia alimentar. No Brasil, o arroz é o terceiro produto mais importante depois da soja e do milho, correspondendo a aproximadamente 11 milhões de toneladas. O Rio Grande do Sul ocupa um lugar de destaque na cultura, respondendo por $50 \%$ da produção nacional e $80 \%$ do arroz irrigado.

Embora o cenário da cultura do arroz irrigado seja de alta tecnologia, o uso de sementes certificadas para a implantação das lavouras tem sido bastante baixo. É comum no Rio Grande do Sul, os agricultores separarem a melhor parte da lavoura para ser usada como semente na próxima safra, sem qualquer inspeção ou algum processo que ateste a qualidade dessa semente, embora seja notório que a taxa de utilização de sementes (TUS) está intimamente ligada com a produtividade das cultivares (Carraro, 2001). Além disso, outros problemas também são desencadeados pela baixa taxa de utilização de sementes, como o emprego de elevadas densidades de semeadura, devido a falta de conhecimento da capacidade germinativa das sementes; enquanto a pesquisa recomenda 100 a $150 \mathrm{~kg} \mathrm{ha}^{-1}$ é comum serem usados $200 \mathrm{a}$ $250 \mathrm{~kg} \mathrm{ha}^{-1}$.

Vigor de sementes são propriedades que determinam o potencial para uma rápida e uniforme emergência e o desenvolvimento de plântulas normais sob uma ampla faixa de condições ambientais (AOSA, 1983). O vigor máximo é atingido quando, durante o processo de desenvolvimento, as sementes alcançam a maior massa seca, o chamado ponto de maturidade fisiológica.

No entanto, a influência do vigor das sementes sobre a produtividade das culturas resultantes tem sido um tanto contraditória na literatura. Alguns trabalhos reportaram efeitos significativos de vigor de sementes sobre o rendimento de sementes em culturas anuais, associando esses efeitos a densidades populacionais em níveis subótimos, devido ao baixo potencial de estabelecimento de plântulas no campo (Schuch \& Lin, 1982), ou semeaduras mais tardias que o normal (Khah et al., 1989).

Por outro lado, Popinigis (1973), Camargo \& Vaughan (1973) e Krishna et al. (1997) constataram maior rendimento de sementes em diversas culturas, causado pela utilização de sementes de vigor mais elevado.

Trabalhos recentes têm indicado efeito direto do vigor das sementes sobre o rendimento de grãos. Scheeren (2002) observou estreita relação entre o vigor de sementes e a produtividade, constatando que o aumento na produtividade devido ao uso de sementes de alto vigor atingiu valores de até $10 \%$ na cultura da soja. Kolchinski (2003), avaliando plantas individuais de soja, observou redução em torno de $28 \%$ no rendimento de grãos, em função da variação no vigor das sementes.

A densidade de semeadura é um dos fatores importantes a ser considerado na implantação de uma lavoura para que uma população ideal de plantas seja atingida. Alguns trabalhos indicaram que 100 a $200 \mathrm{~kg} \mathrm{ha}^{-1}$ não tiveram grande influência sobre rendimento de cultivares modernas de arroz. Sousa et al. (1995) concluíram que no sistema de plantio direto a produtividade da cultivar BR-IRGA 410 não foi afetada quando foram usados entre 90 a $210 \mathrm{~kg}$ de sementes por ha. Rieffel Neto et al. (2000) verificaram que menores densidades de semeadura podem ser recomendadas, desde que haja condições de cultivo com adequado controle de plantas daninhas, correto manejo da irrigação e semente de boa qualidade. Sementes de alta qualidade fisiológica permitem uma rápida emergência e estabelecimento das plantas, aspectos que facilitam o manejo da cultura e proporcionam menores riscos ao ambiente e ao capital investido.

O objetivo desse trabalho foi avaliar o comportamento de lotes de sementes com níveis de qualidade fisiológica distintos, em diferentes densidades de semeadura, no rendimento e na qualidade industrial de grãos em arroz irrigado.

\section{MATERIALE MÉTODOS}

O experimento foi conduzido em condições de campo, nos anos agrícolas 2000/2001 e 2001/2002 no Centro Agropecuário da Palma, pertencente à Universidade Federal de Pelotas (CAP/UFPel), localizado no município de Capão do Leão - RS. O CAP/UFPel está situado na Encosta do Sudoeste do Estado do Rio Grande do Sul, a $31^{\circ} 45^{\prime} 45^{\prime \prime}$ de latitude sul e $52^{\circ} 19^{\prime} 55^{\prime \prime}$ de longitude Oeste de Greenwich.

$\mathrm{O}$ experimento foi instalado em um Planossolo, pertencente à unidade de mapeamento Pelotas. Foram testadas, em uma combinação fatorial, em dois anos agrícolas (2000/ 2001 e 2001/2002), dois níveis de qualidade fisiológica de sementes e diferentes densidades de semeadura. O nível de qualidade fisiológica alta correspondeu a lotes de sementes com índices de germinação acima de $95 \%$ e o nível de qualidade fisiológica baixa correspondeu a lotes com percentagem de germinação entre 80 a $85 \%$, conforme a Tabela 1 .

As densidades de semeadura utilizadas foram $80,140 \mathrm{e}$ $200 \mathrm{~kg}$ de sementes por hectare, em 2000/2001, e 80 e 150 
TABELA 1. Caracterização dos lotes de sementes de arroz por meio da germinação e vigor (envelhecimento acelerado, teste de frio e emergência no campo), nas safras 2000/2001 e 2001/2002, CAP/UFPel, Capão do Leão, RS.

\begin{tabular}{|c|c|c|c|c|c|}
\hline $\begin{array}{l}\text { Qualidade } \\
\text { fisiológica }\end{array}$ & Lotes & $\begin{array}{c}\text { Teste de } \\
\text { germinação }\end{array}$ & $\begin{array}{l}\text { Envelhecimento } \\
\text { acelerado }\end{array}$ & $\begin{array}{l}\text { Teste de } \\
\text { frio }\end{array}$ & $\begin{array}{l}\text { Emergência } \\
\text { no campo }\end{array}$ \\
\hline \multicolumn{6}{|c|}{$2000 / 2001$} \\
\hline \multirow{4}{*}{ Alta } & 1 & 97 & 95 & 94 & 92 \\
\hline & 2 & 98 & 94 & 94 & 93 \\
\hline & 3 & 98 & 95 & 95 & 93 \\
\hline & 4 & 97 & 96 & 94 & 93 \\
\hline \multirow{4}{*}{ Baixa } & 5 & 84 & 80 & 78 & 78 \\
\hline & 6 & 85 & 80 & 75 & 77 \\
\hline & 7 & 85 & 78 & 82 & 82 \\
\hline & 8 & 83 & 79 & 76 & 75 \\
\hline \multicolumn{6}{|c|}{$2001 / 2002$} \\
\hline \multirow{2}{*}{ Alta } & 1 & 98 & 94 & 95 & 96 \\
\hline & 2 & 98 & 94 & 94 & 97 \\
\hline \multirow{2}{*}{ Baixa } & 3 & 84 & 78 & 80 & 79 \\
\hline & 4 & 85 & 80 & 78 & 85 \\
\hline
\end{tabular}

$\mathrm{kg}$ de sementes por hectare, em 2001/2002. Os diferentes lotes de sementes da cultivar IRGA 417 foram obtidos de produtores de sementes cadastrados junto à CESM/RS. Utilizou-se o delineamento experimental em blocos ao acaso, com três repetições, em 2000/2001, e quatro repetições, em 2001/2002. As parcelas foram constituídas de nove linhas de cinco metros, em 2000/2001, e de seis linhas de cinco metros, em 2001/2002, espaçadas de $17 \mathrm{~cm}$.

A semeadura foi realizada em novembro de 2000 e 2001 , no sistema convencional, e as colheitas realizadas em março dos anos subseqüentes. A adubação foi realizada conforme os resultados da análise do solo. Também foi feito o controle químico de plantas invasoras e iniciada a irrigação, por inundação, aos 35 dias após a emergência.

Foram marcados 2 metros em duas linhas de cada parcela, onde foram contados o número de plantas emergidas, e o resultado transformado em número de plantas por $\mathrm{m}^{2}$. Por ocasião da maturação, foram contadas as panículas presentes nesses dois metros de linha e determinado o número de panículas por $\mathrm{m}^{2}$. Foram coletadas, ao acaso, 20 panículas por parcela, sendo determinado o número de grãos por panícula, após a contagem dos grãos. A massa de 1000 grãos foi determinada pela pesagem de uma amostra de 1000 grãos pertencentes à área útil das parcelas. A percentagem de sementes verdes foi determinada por meio da separação visual e contagem do número de sementes verdes na amostra utilizada para a determinação da massa de 1000 grãos e o resultado expresso em percentagem.

$\mathrm{O}$ índice de colheita foi determinado pela colheita das plantas existentes em um metro de fileira por parcela, as quais foram trilhadas manualmente. O material vegetativo e os grãos foram submetidos à secagem em estufa a $55^{\circ} \mathrm{C}$ por 72 horas e pesados separadamente. $\mathrm{O}$ índice de colheita foi calculado pela fórmula: $\mathrm{IC}=$ rendimento de grãos/rendimento de biomassa x 100. A estatura das plantas foi determinada pela avaliação de 20 plantas escolhidas ao acaso dentre as plantas presentes na área útil da parcela, com auxílio de trena graduada.

O rendimento de grãos foi obtido pela colheita das áreas úteis das parcelas, transformado em $\mathrm{kg} \mathrm{ha}^{-1}$ e corrigido para $13 \%$ de umidade.

O rendimento de grãos inteiros foi determinado utilizando uma amostra de $100 \mathrm{~g}$ com $13 \%$ de umidade, que foram submetidos ao engenho de provas. Após a retirada dos grãos não descascados, foram separadas e pesadas as frações grãos inteiros e quebrados, e calculada a percentagem de grãos inteiros.

Os dados experimentais foram submetidos à análise de variância e os efeitos dos tratamentos avaliados pelo teste $\mathrm{F}$, enquanto as médias dos tratamentos foram comparadas entre si pelo teste de Duncan, em nível de 5\% de probabilidade.

\section{RESULTADOS E DISCUSSÃO}

A análise da variância não indicou interação entre qualidade fisiológica de sementes e densidade de semeadura durante os dois anos avaliados. 
A diferença de qualidade fisiológica de sementes afetou o estabelecimento no campo da cultura do arroz, como pode ser observado na Tabela 2, onde a utilização de sementes de menor qualidade fisiológica proporcionou um menor número de plantas por metro quadrado, nos dois anos agrícolas avaliados. Na Tabela 3, observa-se um efeito direto da densidade de semeadura sobre a população de plantas estabelecida no campo.

O uso de sementes de alta qualidade fisiológica proporcionou a produção de um maior número de panículas por metro quadrado, embora não tenha ocorrido diferença significativa $(\mathrm{P}>0,05)$ no ano 2000/20001 (Tabela 2). O aumento na densidade de semeadura também provocou acréscimos no número de panículas por metro quadrado (Tabela 3). Observa-se, também ,na Tabela 2, que o uso de sementes de alta qualidade fisiológica reduziu o número de panículas por planta nos dois anos avaliados, provavelmente causado por um efeito compensatório devido à ocorrência de perfilhamento mais intenso nas densidades populacionais mais baixas. Fato semelhante ocorreu em função da variação na densidade de semeadura (Tabela 3). Segundo Nedel et al. (1988), a redução do número de perfilhos por planta, devido ao acréscimo na população de plantas, estaria relacionada ao aumento na concentração de auxinas nas plantas de arroz, em conseqüência do sombreamento das folhas inferiores, causando acréscimo na dominância apical e reduzindo, conseqüentemente, o desenvolvimento das gemas laterais ou perfilhos.

O número de grãos por panícula tendeu a reduzir com o uso de sementes de alta qualidade fisiológica (Tabela 2). Esse efeito aparentemente está associado com o acréscimo na população de plantas causada pelo uso de sementes de alta qualidade fisiológica, uma vez que o acréscimo na densidade de semeadura (Tabela 3) também provocou redução no número de grãos por panícula, devido aos acréscimos ocorridos na população de plantas por metro quadrado.

TABELA 2. Componentes do rendimento e produtividade de grãos de arroz irrigado, em função de diferentes níveis de qualidade fisiológica das sementes (médias de diferentes densidades de semeadura), em dois anos agrícolas, CAP/UFPel, Capão do Leão, RS.

\begin{tabular}{|c|c|c|c|c|c|c|}
\hline $\begin{array}{l}\text { Níveis de } \\
\text { vigor }\end{array}$ & $\begin{array}{l}\text { Plantas/ } \\
\mathrm{m}^{2}\end{array}$ & $\begin{array}{l}\text { Panículas/ } \\
\mathrm{m}^{2}\end{array}$ & $\begin{array}{l}\text { Panículas/ } \\
\text { planta }\end{array}$ & $\begin{array}{l}\text { Grãos/ } \\
\text { panícula }\end{array}$ & $\begin{array}{l}\text { Massa de } 1000 \text { grãos } \\
(\mathrm{g})\end{array}$ & $\begin{array}{l}\text { Produtividade de } \\
\text { grãos (kg hâ) }\end{array}$ \\
\hline & \multicolumn{6}{|c|}{$2000 / 2001$} \\
\hline Alto & $163 \mathrm{a}$ & $361 \mathrm{a}$ & $2,73 \mathrm{~b}$ & $76,6 \mathrm{~b}$ & $26,25 \mathrm{a}$ & $7588 \mathrm{a}$ \\
\hline Baixo & $135 \mathrm{~b}$ & $347 \mathrm{a}$ & $3,36 \mathrm{a}$ & $81,6 \mathrm{a}$ & $25,81 \mathrm{~b}$ & $6966 \mathrm{~b}$ \\
\hline \multirow[t]{2}{*}{$\mathrm{CV}(\%)$} & 37,62 & 15,77 & 35,16 & 10,66 & 3,33 & 16,10 \\
\hline & \multicolumn{6}{|c|}{$2001 / 2002$} \\
\hline Alto & $310 \mathrm{a}$ & $466 \mathrm{a}$ & $1,64 \mathrm{~b}$ & $80,3 \mathrm{a}$ & $26,08 \mathrm{a}$ & $7346 \mathrm{a}$ \\
\hline Baixo & $266 \mathrm{~b}$ & $432 \mathrm{~b}$ & $1,79 \mathrm{a}$ & $85,3 \mathrm{a}$ & $25,61 \mathrm{~b}$ & $6686 \mathrm{~b}$ \\
\hline $\mathrm{CV}(\%)$ & 10,44 & 7,23 & 7,81 & 12,48 & 3,07 & 8,01 \\
\hline
\end{tabular}

Médias seguidas da mesma letra, na coluna, não diferem pelo teste de Duncan, em nível de 5\%.

TABELA 3. Componentes do rendimento e produtividade de grãos de arroz irrigado, em função de diferentes densidades de semeadura (médias de dois níveis de qualidade fisiológica de sementes), em dois anos agrícolas, CAP/UFPel, Capão do Leão, RS.

\begin{tabular}{ccccccc}
\hline $\begin{array}{c}\text { Densidade } \\
\left(\mathrm{kg} \mathrm{ha}^{-1}\right)\end{array}$ & $\begin{array}{c}\text { Plantas/ } \\
\mathrm{m}^{2}\end{array}$ & $\begin{array}{c}\text { Panículas/ } \\
\mathrm{m}^{2}\end{array}$ & $\begin{array}{c}\text { Panículas/ } \\
\text { planta }\end{array}$ & $\begin{array}{c}\text { Grãos/ } \\
\text { panícula }\end{array}$ & $\begin{array}{c}\text { Massa de } 1000 \\
\text { grãos }(\mathrm{g})\end{array}$ & $\begin{array}{c}\text { Produtividade de } \\
\text { grãos (kg hä })\end{array}$ \\
\hline & & \multicolumn{6}{c}{$2000 / 2001$} \\
80 & $76 \mathrm{c}$ & $316 \mathrm{~b}$ & $4,40 \mathrm{a}$ & $88,7 \mathrm{a}$ & $25,90 \mathrm{a}$ & $7437 \mathrm{a}$ \\
140 & $143 \mathrm{~b}$ & $362 \mathrm{a}$ & $2,85 \mathrm{~b}$ & $77,7 \mathrm{~b}$ & $26,11 \mathrm{a}$ & $7358 \mathrm{a}$ \\
200 & $227 \mathrm{a}$ & $382 \mathrm{a}$ & $1,88 \mathrm{c}$ & $70,9 \mathrm{c}$ & $26,09 \mathrm{a}$ & $7037 \mathrm{a}$ \\
\hline $\mathrm{CV}(\%)$ & 37,62 & 15,77 & 35,16 & 10,66 & 3,33 & 16,10 \\
\hline & & \multicolumn{7}{c}{$2001 / 2002$} \\
150 & $196 \mathrm{~b}$ & $419 \mathrm{~b}$ & $2,15 \mathrm{a}$ & $84,0 \mathrm{a}$ & $25,70 \mathrm{a}$ & $7049 \mathrm{a}$ \\
\cline { 2 - 7 } & $380 \mathrm{a}$ & $479 \mathrm{a}$ & $1,28 \mathrm{~b}$ & $81,5 \mathrm{a}$ & $25,99 \mathrm{a}$ & $6983 \mathrm{a}$ \\
\hline $\mathrm{CV}(\%)$ & 10,44 & 7,23 & 7,81 & 12,48 & 3,07 & 8,01 \\
\hline
\end{tabular}

Médias seguidas da mesma letra, na coluna, não diferem pelo teste de Duncan, em nível de 5\%. 
O uso de sementes de baixa qualidade fisiológica provocou redução na massa de 1000 grãos nos dois anos agrícolas avaliados (Tabela 2). Esse parece ser, também, um efeito direto da qualidade fisiológica inicial das sementes utilizadas, uma vez que a variação na população de plantas, provocada pela variação na densidade de semeadura, não afetou essa mesma característica. Da mesma forma, Sousa et al. (1995) e Crusciol et al. (2000) não constataram efeito da variação na densidade de semeadura sobre a massa de 1000 sementes.

O rendimento de grãos foi afetado pelo nível de qualidade fisiológica das sementes. $\mathrm{O}$ uso de sementes de alta qualidade fisiológica proporcionou acréscimos no rendimento de $8,2 \mathrm{e}$ $9,0 \%$ nos anos 2000/2001 e 2001/2002, que corresponde a 622 e $660 \mathrm{~kg} \mathrm{ha}^{-1}$, respectivamente (Tabela 2).

Alguns trabalhos relatando efeitos significativos de vigor de sementes sobre o rendimento de grãos em culturas anuais associam esses efeitos a densidades populacionais em níveis subótimos, devido ao baixo potencial de estabelecimento de plântulas no campo (Schuch \& Lin, 1982), ou semeaduras mais tardias que o normal (Khah et al., 1989). Os acréscimos constatados na Tabela 2, porém, são devidos aos efeitos diretos da qualidade fisiológica das sementes sobre o rendimento de grãos, uma vez que a variação na densidade de semeadura não provocou efeito sobre a produtividade de grãos, nos dois anos avaliados (Tabela 3 ), tendo apresentado inclusive tendência de aumento no ano 2000/2001, embora não tenha sido significativo $(\mathrm{P}>0,05)$. Estes resultados podem estar relacionados ao fato das semeaduras terem sido realizadas dentro da época recomendada para o cultivo do arroz na região. Trabalhos recentes também têm mostrado efeito direto do vigor das sementes sobre o rendimento de grãos (Scheeren, 2002; Kolchinski, 2003).

A estatura das plantas não foi afetada pela variação no nível de qualidade fisiológica das sementes e na densidade de semeadura, em nenhum dos anos agrícolas avaliados (Tabelas 4 e 5). Também não foi observada ocorrência de acamamento em nenhum dos tratamentos avaliados, por se tratar de uma cultivar de porte moderno e responsiva a elevados aportes de adubação nitrogenada (Terres, 1998).

O índice de colheita foi avaliado somente no ano 2001/ 2002 , onde a variação na qualidade fisiológica das sementes não afetou a alocação de biomassa seca nas sementes, enquanto que a utilização de densidades de semeadura mais elevadas reduziu a proporção de biomassa seca alocada nas sementes (Tabelas 4 e 5). Em consonância, Abreu \& Schuch (2002) constataram redução no índice de colheita com o aumento na população de plantas, enquanto Schuch et al. (2000a) observaram acréscimo no índice de colheita em populações mais elevadas. Para Donald \& Hamblin (1976), a densidade de semeadura, a adubação nitrogenada e a disponibilidade de água são os principais fatores que afetam o índice de colheita em cereais.

O rendimento de grãos inteiros não foi afetado nem pelo nível de qualidade fisiológica das sementes, nem pela variação na densidade de semeadura (Tabelas 4 e 5). Esse comportamento contraria a hipótese de que menores populações de plantas poderiam reduzir a qualidade industrial de grãos de arroz. Menores populações de plantas, proporcionando abundante perfilhamento, provocariam maior grau de desuniformidade de maturação entre grãos oriundos de perfilhos de diferentes ordens. Da mesma forma, Canellas et al. (1997) esperavam que maiores densidades de semeadura resultassem em melhor rendimento de engenho, o que não foi confirmado experimentalmente.

$\mathrm{O}$ uso de sementes de baixa qualidade fisiológica provocou acréscimos de 5,6 e 3,2 pontos percentuais na percentagem de sementes verdes nos anos 2000/2001 e 2001/ 2002, respectivamente (Tabela 4), indicando um aumento na desuniformidade de maturação, devido a baixa qualidade fisiológica das sementes. Essa desuniformidade de maturação está, provavelmente, associada a maior desuniformidade de emergência no campo dos lotes de semente de menor qualidade fisiológica, conforme foi observado por Schuch et al. (2000b) e Höfs (2003), o que ocasionaria retardamento na maturação dessas plantas. Essa variação na uniformidade de maturação não está associada à variação na população de plantas e a conseqüente variação no número de perfilhos por plantas, como pode ser observado na Tabela 5. O aumento na desuniformidade de maturação provocado pelo uso de sementes de baixa qualidade fisiológica, não se refletiu na qualidade industrial dos grãos de arroz, avaliada pelo rendimento de grãos inteiros (Tabela 4).

O uso de sementes de baixa qualidade fisiológica provocou redução no rendimento de grãos por hectare devido à redução no número de panículas por metro quadrado e redução na massa de 1000 grãos, não estando associado à redução na população de plantas ocasionada pela baixa qualidade fisiológica das sementes. A redução do rendimento de grãos está, provavelmente, associada à maior desuniformidade de emergência e, conseqüentemente, ao maior grau de competição intraespecífica que estariam sujeitas as plantas emergidas mais tardiamente, o que se refletiria em redução nos componentes do rendimento. 
TABELA4. Estatura de plantas, índice de colheita (I.C.), rendimento de grãos inteiros e percentagem de sementes verdes, em função de diferentes níveis de qualidade fisiológica das sementes (médias de diferentes densidades de semeadura), em dois anos agrícolas, CAP/UFPel, Capão do Leão, RS.

\begin{tabular}{ccccc}
\hline $\begin{array}{c}\text { Níveis de } \\
\text { vigor }\end{array}$ & $\begin{array}{c}\text { Estatura de } \\
\text { plantas (cm) }\end{array}$ & $\begin{array}{c}\text { I.C. } \\
(\%)\end{array}$ & $\begin{array}{c}\text { Rendimento de } \\
\text { grãos inteiros (\%) }\end{array}$ & $\begin{array}{c}\text { Sementes } \\
\text { verdes (\%) }\end{array}$ \\
\cline { 2 - 5 } Alto & & & $2000 / 2001$ & \\
Baixo & $85 \mathrm{a}$ & - & $57,6 \mathrm{a}$ & $11,4 \mathrm{~b}$ \\
\hline CV(\%) & $84 \mathrm{a}$ & - & $58,5 \mathrm{a}$ & $17,0 \mathrm{a}$ \\
\hline & 2,46 & & 14,95 & 31,06 \\
\hline Alto & & & $2001 / 2002$ & $11,8 \mathrm{~b}$ \\
Baixo & $86 \mathrm{a}$ & $51,0 \mathrm{a}$ & $59,1 \mathrm{a}$ & $15,0 \mathrm{a}$ \\
\hline $\mathrm{CV}(\%)$ & 2,01 & $51,3 \mathrm{a}$ & $57,0 \mathrm{a}$ & 11,55 \\
\hline
\end{tabular}

Médias seguidas da mesma letra, na coluna, não diferem pelo teste de Duncan, em nível de 5\%.

TABELA5. Estatura de plantas, índice de colheita (I.C.), rendimento de grãos inteiros e percentagem de sementes verdes, em função de diferentes densidades de semeadura (médias de dois níveis de qualidade fisiológica), em dois anos agrícolas, CAP/ UFPel, Capão do Leão, RS.

\begin{tabular}{|c|c|c|c|c|}
\hline $\begin{array}{c}\text { Densidade } \\
\left(\mathrm{kg} \mathrm{ha}^{-1}\right)\end{array}$ & $\begin{array}{l}\text { Estatura de } \\
\text { plantas }(\mathrm{cm})\end{array}$ & $\begin{array}{l}\text { I.C. } \\
(\%)\end{array}$ & $\begin{array}{l}\text { Rendimento de } \\
\text { grãos inteiros (\%) }\end{array}$ & $\begin{array}{c}\text { Sementes } \\
\text { verdes (\%) }\end{array}$ \\
\hline & \multicolumn{4}{|c|}{$2000 / 2001$} \\
\hline 80 & $84,4 \mathrm{a}$ & - & 58,9 a & $14,6 \mathrm{a}$ \\
\hline 140 & $84,7 \mathrm{a}$ & - & $55,2 \mathrm{a}$ & $13,3 \mathrm{a}$ \\
\hline 200 & $83,9 \mathrm{a}$ & - & $59,9 \mathrm{a}$ & $14,4 \mathrm{a}$ \\
\hline $\mathrm{CV}(\%)$ & 2,46 & & 14,95 & 31,06 \\
\hline & \multicolumn{4}{|c|}{$2001 / 2002$} \\
\hline 80 & 85,9 a & $51,9 \mathrm{a}$ & $58,1 \mathrm{a}$ & $12,6 \mathrm{a}$ \\
\hline 150 & $85,2 \mathrm{a}$ & $50,5 \mathrm{~b}$ & $57,9 \mathrm{a}$ & $14,1 \mathrm{a}$ \\
\hline $\mathrm{CV}(\%)$ & 2,01 & 3,69 & 10,76 & 11,55 \\
\hline
\end{tabular}

Médias seguidas da mesma letra, na coluna, não diferem pelo teste de Duncan, em nível de 5\%.

Diversos trabalhos avaliaram o efeito da diferença de emergência de plantas adjacentes na linha de semeadura sobre a competição intraespecífica. Em milho, Merotto Júnior et al. (1999) observaram que as plantas de emergência atrasada apresentaram menor rendimento de grãos, demonstrando que as plantas que emergem tardiamente são dominadas, acontecendo, porém, uma compensação por parte das plantas que emergiram primeiro.

Neste sentido, Nafziger et al. (1991), também trabalhando com a cultura do milho, constataram que o aumento na proporção de plantas de emergência antecipada na população elevou o rendimento de grãos individuais destas, com redução progressiva no rendimento das plantas que emergiram depois. Porém, de acordo com Merotto Júnior et al. (1999), esta compensação por parte das plantas que emergiram antes não é suficiente para proporcionar rendimentos de grãos semelhantes ao de uma comunidade com emergência uniforme.

Egli (1993) também constatou que as plantas de soja emergidas precocemente sempre tiveram vantagem competitiva sobre as plantas emergidas mais tardiamente, em posições alternadas na mesma fila; essa vantagem se refletiu em maior rendimento de grãos por planta. Walker et al. (1988) enfatizam que as plantas que se desenvolvem mais rápida e simultaneamente, tanto em estatura como em área foliar, competem mais eficientemente pela luz. Nesse sentido, Counce et al. (1989) constataram que o aumento na uniformidade entre plantas, dentro de uma população, causou incremento no rendimento de grãos, devido à redução no número de plantas sombreadas e menos produtivas, onde as plantas emergidas mais tardiamente estariam sujeitas a uma maior intensidade de competição. 
Outro fator que poderia estar contribuindo para os maiores rendimentos de grãos obtidos em populações de plantas oriundas de sementes de alta qualidade fisiológica, seria a produção de plântulas com maior índice de área foliar e maior taxa de crescimento nos estádios iniciais de desenvolvimento, como observado por Schuch et al. (2000b) e Höfs (2003). Schuch et al. (2000c) observaram que diferenças no vigor das sementes causaram diferenças na produção de biomassa seca em aveia preta, durante todo o período vegetativo, tendo as plantas oriundas de sementes de alto vigor apresentado produção de biomassa seca até 31\% superior às oriundas de sementes de baixo vigor, durante o período vegetativo.

Adicionalmente, o aumento na desuniformidade de maturação, constatado pelo acréscimo na percentagem de sementes verdes, poderia estar contribuindo para a redução na massa de 1000 grãos, pois parte dos grãos estariam sendo colhidos antes de atingirem a maturação plena.

Por outro lado, constata-se a possibilidade de obtenção de elevados rendimentos de grãos, sem prejuízo da qualidade industrial, utilizando densidades de semeadura bem inferiores àquelas atualmente praticadas em cultivos comerciais de arroz irrigado. $\mathrm{O}$ uso de densidades de semeadura mais baixas tem sido limitado, na atualidade, pelo uso de sementes próprias de baixa qualidade fisiológica ou mesmo sem a qualidade atestada e, também, pela deficiente distribuição de sementes pelas semeadoras existentes no mercado. Nesse sentido, Butierres (2003) desenvolveu tecnologia que proporciona excelente distribuição de sementes com densidades reduzidas de semeadura utilizando semeadora com sistema pneumático de distribuição de sementes.

\section{CONCLUSÕES}

O uso de sementes de baixa qualidade fisiológica provoca redução do rendimento de grãos em arroz irrigado, não estando esses efeitos associados com alterações na população de plantas;

O uso de sementes de alta qualidade fisiológica proporciona acréscimos próximos a $10 \%$ no rendimento de grãos em arroz irrigado;

O uso de sementes de baixa qualidade fisiológica provoca desuniformidade na maturação e redução na massa de 1000 grãos, não afetando o rendimento de grãos inteiros;

Redução na densidade de semeadura não afeta a produtividade de grãos, a uniformidade de maturação e o rendimento de grãos inteiros.

\section{REFERÊNCIAS}

ABREU, G.T.; SCHUCH, L.O.B. Análise do crescimento e utilização de nitrogênio em aveia branca (Avena sativa L.) em função da população de plantas. Revista Brasileira de Agrociência, Pelotas, v. 8, n. 2, p. 111-116, 2002.

ASSOCIATION OF OFFICIAL SEED ANALYSTS. Seed vigor testing commitee. Seed vigor testing handbook. East Lansing: AOSA, 1983. 88p. (Contribution, 32).

BUTIERRES, E. Desempenho do mecanismo semeador pneumático a vácuo para arroz. 2003. 85f. Tese (Doutorado em Ciência e Tecnologia de Sementes) - Faculdade de Agronomia Eliseu Maciel, Universidade Federal de Pelotas, Pelotas, 2003.

CAMARGO, C.P.; VAUGHAN, L.E. Effect of seed vigor on field performance and yield of grain sorghum (Sorghum bicolor (L.) Moench.). Proceedings Association of Official Seed Analysts, Madison, n.63, p. 135-147, 1973.

CANELLAS, L.P.; SANTOS, G.A.; MARCHEZAN, E. Efeito de práticas de manejo sobre o rendimento de grãos e a qualidade industrial dos grãos em arroz irrigado. Ciência Rural, Santa Maria, v.27, n.3, p. 375-379, 1997.

CARRARO, I.M. Semente: insumo nobre. Seed News. Pelotas, n.5, p. 34-35, 2001.

COUNCE, P.A.; MOLDENHAUER, K.A.K.; MARX, D.B. Rice yield and plant yield variability responses to equidistant spacing. Crop Science, Madison, v.29, p.175-179, 1989.

CRUSCIOL, C.A.C.; MACHADO, J.R.; ARF, O.; RODRIGUES, R.A.F. Produtividade do arroz irrigado por aspersão em função do espaçamento e da densidade de semeadura. Pesquisa Agropecuária Brasileira, Brasília, v.35, n.6, p.1093-1100, 2000.

DONALD, C.M.; HAMBLIN, J. The biological yield and harvest of cereals as agronomic and plant breeding criteria. Advances in Agronomy, New York, v.28, p. 351-405, 1976.

EGLI, D.B. Relationship of uniformity of soybean seedling emergence to yield. Journal of Seed Technology, East Lansing, v. 17, n. 1, p. 22-28, 1993.

HÖFS, A. Vigor de sementes de arroz e desempenho da cultura. 2003. 44f. Tese (Doutorado em Ciência e Tecnologia de Sementes) - Faculdade de Agronomia Eliseu Maciel, Universidade Federal de Pelotas, Pelotas, 2003.

KHAH, E.M.; ROBERTS E.H.; ELLIS R.H. Effects of seed aging on growth and yield of spring wheat at different population plantpopulation densities. Field Crops Research, New York, v.20, p. 175-190, 1989.

KOLCHINSKI, E.M. Vigor de sementes e competição intraespecífica em soja. 2003. 46f. Tese (Doutorado em Ciência e Tecnologia de Sementes) - Faculdade de Agronomia Eliseu Maciel, Universidade Federal de Pelotas, Pelotas, 2003.

KRISHNA, A.; JAGADADISH, G.V.; DESHPANDE, V.K.; PRASANNA, K.P.R. Effect of seed vigor levels on field performance and relationship between seed vigor tests and field emergence in sunflower hybrids. Journal of Agricultural Sciences, Cambridge, v. 10, n. 1, p. 112-116, 1997. 
MEROTTO JÚNIOR, A.; SANGOI, L.; ENDER, M.; GUIDOLIN, A.F.; HAVERROTH, H.S. A desuniformidade de emergência reduz o rendimento de grãos de milho. Ciência Rural, Santa Maria, v. 29, n. 4, p. 595-601, 1999.

NAFZIGER, E.D.; CARTER, P.R.; GRAHAM, E.E. Response of corn to uneven emergence. Crop Science, Madison, v. 31, p. 811$815,1991$.

NEDEL, J.L.; ASSIS, F.N.; CARMONA, P.S. A planta de arroz: morfologia e fisiologia. In: PESKE, S.T.; NEDEL, J. L.; BARROS, A.C.S.A. (Ed.). Produção de arroz irrigado. Pelotas: Editora Universitária, 1998. p. 351-412.

POPINIGIS, F. Effects of the physiological quality of seed on field performance of soybean as affected by plant population. 1973.85 f. Thesis (PhD) - Mississipi State University, Mississipi, 1973.

RIEFFEL NETO, S.R.; SILVA, P.R.F.; MENEZES, V.G.; MARIOT, C.H.P. Resposta de arroz irrigado ao arranjo de plantas. Pesquisa Agropecuária Brasileira, Brasília, v.35, n.12, p. 2383-2390, 2000.

SCHEEREN, B. Vigor de sementes de soja e produtividade. 2002. 45f. Tese (Doutorado em Ciência e Tecnologia de Sementes) Faculdade de Agronomia Eliseu Maciel, Universidade Federal de Pelotas, Pelotas, 2002.

SCHUCH, L.O.B.; LIN, S.S. Atraso na colheita sobre emergência no campo e desempenho de plantas de trigo. Pesquisa
Agropecuária Brasileira, Brasília, v.17, n.11, p. 1585-1589, 1982. SCHUCH, L.O.B.; NEDEL, J.L.; ASSIS, F.N.; MAIA, M.S. Vigor de sementes e populações de aveia preta: II Desempenho e utilização de nitrogênio. Scientia Agrícola, Piracicaba, v.57, n.1, p. 121-127, 2000a.

SCHUCH, L.O.B.; NEDEL, J.L.; ASSIS, F.N.; MAIA, M.S. Emergência a campo e crescimento inicial de aveia preta em resposta ao vigor de sementes. Revista Brasileira de Agrociência. Pelotas, v. 6, n. 2, p. 97-101, 2000b.

SCHUCH, L.O.B.; NEDEL, J.L.; ASSIS, F.N.; MAIA, M.S. Vigor de sementes e análise de crescimento de aveia preta. Scientia Agrícola. Piracicaba, v. 57, n. 2, p. 305-312, 2000c.

SOUSA, R.O.; GOMES, A.S.; MARTINS, J.F.S.; PEÑA, Y.A. Densidade de semeadura e espaçamento entre linhas para arroz irrigado no sistema plantio direto. Revista Brasileira de Agrociência, Pelotas, v.1, n.2, p.69-74, 1995.

TERRES, A.L. Descrição de cultivares de arroz. In: PESKE, S.T.; NEDEL, J. L.; BARROS, A.C.S.A. (Ed.). Produção de arroz irrigado. Pelotas: Editora Universitária, 1998. p. 423-434.

WALKER, G.K.; BLACKSHAW, R.E.; DEKKER, L. Leaf area and competition for light between plant species using direct sunlight transmission. Weed Technology, Champaingn, v. 2, n. 2, p. 159$165,1988$. 